\title{
Renewables, Reliability and Efficiency in Electricity Markets
}

Frank A. Felder and Marie Petitet 


\section{About KAPSARC}

The King Abdullah Petroleum Studies and Research Center (KAPSARC) is a non-profit global institution dedicated to independent research into energy economics, policy, technology and the environment across all types of energy. KAPSARC's mandate is to advance the understanding of energy challenges and opportunities facing the world today and tomorrow, through unbiased, independent, and high-caliber research for the benefit of society. KAPSARC is located in Riyadh, Saudi Arabia.

This publication is also available in Arabic.

\section{Legal Notice}

(c) Copyright 2021 King Abdullah Petroleum Studies and Research Center ("KAPSARC"). This Document (and any information, data or materials contained therein) (the "Document") shall not be used without the proper attribution to KAPSARC. The Document shall not be reproduced, in whole or in part, without the written permission of KAPSARC. KAPSARC makes no warranty, representation or undertaking whether expressed or implied, nor does it assume any legal liability, whether direct or indirect, or responsibility for the accuracy, completeness, or usefulness of any information that is contained in the Document. Nothing in the Document constitutes or shall be implied to constitute advice, recommendation or option. The views and opinions expressed in this publication are those of the authors and do not necessarily reflect the official views or position of KAPSARC. 


\section{Key Points}

The choice to use electricity markets to transition to an ultra-high renewable electricity sector depends on whether a high level of reliability and efficiency can be achieved. This study presents a reliability, resiliency and adaptability policy framework for a liberalized power system with a high share of renewables. This framework provides policy insights regarding electricity market reliability and the implications of remuneration mechanisms for renewables. Our analysis shows that it is necessary to reconsider adequacy assessments of liberalized power systems, to enhance the definition of the loss of load probability, and to explicitly consider the probability that the market clears. Under these conditions, electricity markets can theoretically achieve reliability and efficiency with large percentages of variable and intermittent renewable resources with zero or near-zero marginal costs, and market and technical challenges can be addressed.

A reliability, resiliency and adaptability framework should be adopted for policy analyses.

The definition of the value of the lost load should be expanded to incorporate the costs of consumers not having electricity.

Policymakers should revise the definition of the loss of load probability metric to include reliability outcomes for electricity markets.

Many technical options can handle high penetration levels of variable renewables and allow policymakers to learn over time.

Policymakers should consider that renewable remuneration mechanisms may undercut the reliability, resiliency and efficiency of wholesale markets. 


\section{Introduction}

$\mathrm{T}$ ransitioning from fossil fuels in the energy sector is paramount for reducing greenhouse gases, improving air quality and enhancing energy security. At the same time, it is important to maintain affordability and accelerate economic development (Goldthau 2014; Pollitt and Anaya 2016; Schmidt, Schmid, and Sewerin 2019). However, it is unclear whether an affordable transition away from fossil fuels that advances economic development can be achieved (Sorrell 2010). Additionally, many countries have liberalized or are liberalizing their electricity sectors (Joskow 2006a; Urpelainen and Yang 2019). Although substantial evidence supports the efficiency benefits of electricity markets (Fabrizio, Rose, and Wolfram 2007), these findings are tempered and disputed by other studies (De Vries 2005; Joskow 2006b; Pollitt 2009). Thus, understanding whether electricity markets can reliably and cost-effectively transition to renewables with successful implementation and in combination with other policies is critical.

Policymakers have political economic objectives that efficient electricity markets may not support. These goals may include furthering the democratization of policy decision-making, reconfiguring political and economic power, supporting local industries and shifting investment risk from ratepayers to developers (Arentsen and Künneke 1996; Pollitt and Anaya 2016; Tomain 2015; Welton 2018). The pursuit of these other objectives may undercut the benefits of electricity markets (Felder 2011). Moreover, political opposition may prevent policymakers from implementing electricity markets that efficiently and explicitly incorporate environmental externalities via wholesale prices (Grubb and Newbery 2007).

Some argue that energy transition should be carried out cost-effectively to garner and maintain sufficient political support. A cost-effective transition does not waste resources on ineffective and expensive measures. These resources can instead be deployed to meet other pressing societal needs, such as health care, education and raising standards of living (Lu et al. 2015). Others argue that energy transition itself should directly help accomplish these other, broader objectives (Welton 2021).

\section{Energy transitions typically start by decarbonizing} the electric power sector. Numerous low-carbon and non-carbon-emitting alternatives are available, and electricity is a versatile fuel carrier in transportation, heating and some industrial processes (Bompard et al. 2020). Many governments have adopted policies to implement high percentages of renewable energy, including goals of $100 \%$ renewables and ultra-high levels of renewables (Barbose et al. 2016; Chapman and Itaoka 2018; Zappa, Junginger, and van den Broek 2019). In total, 139 countries have developed roadmaps to achieving 100\% renewables (Jacobson 2017). Kroposki (2017) defines ultra-high levels of renewables as penetration above $50 \%$ on an annual energy basis and up to $100 \%$ on an instantaneous basis. We utilize this definition in this study.

Some question whether producing electricity using ultra-high levels of renewable resources should be the preferred end state of the transition away from fossil fuels. Other mitigation options include nuclear power; carbon capture; and recycling, reuse and sequestration (Pollitt and Anaya 2016). Putting this question aside, it is still worth asking whether renewables and electricity markets are inherently incompatible. If they are incompatible, policymakers would probably need to cease their liberalization efforts and re-regulate the electric power sector.

We therefore examine the compatibility of electricity markets with ultra-high levels of renewables based on the fundamentals of engineering and economics that undergird existing markets. 
Although renewables may enhance welfare by improving environmental outcomes, their ultimate impact depends on their costs compared with other technologies and their environmental benefits.

Renewable policies have multiple simultaneous objectives. In addition to reducing greenhouse gas and other emissions, they can serve to develop local nascent renewable energy industries. These policies can also help in forming political coalitions of environmental advocates and business groups and may obscure higher electricity prices from the broader public (Michaels 2008). ${ }^{1}$ We discuss these topics in the contexts of the United States (U.S.) and Europe.

Some have claimed that liberalization and variable and intermittent renewable energy (VIRE) ${ }^{2}$ that have nearly zero marginal costs, such as solar photovoltaic and wind generation, are incompatible with electricity markets (Blazquez et al. 2018; Blazquez, Fuentes, and Manzano 2020). Because VIRE sources are not dispatchable or are extremely limited in their dispatchability, their output cannot be controlled to match supply and demand, which is necessary for ensuring reliability. Furthermore, according to Blazquez et al. (2018), as a market's proportion of renewables grows, wholesale prices are zero or negative for increasingly many hours. Thus, even more out-of-market subsidies are needed to attract the necessary investments to continue to increase the percentage of renewables. ${ }^{3}$
Others argue that the problem lies not in technologies or markets but rather in out-of-market renewable remuneration mechanisms (Brown and Reichenberg 2020; Felder 2011). Still others find that the zero-profit condition is violated with a combination of highly dispatchable and non-dispatchable generation (Eisenack and Mier 2019). Finally, some suggest that VIRE penetration has a ceiling for engineering and economic reasons (Ahmadyar et al. 2017; Denholm and Margolis 2007). Thus, VIRE electricity markets are being challenged both on reliability and efficiency grounds. This article therefore examines the reliability and efficiency of these markets.

The remainder of this paper proceeds as follows. Section 2 proposes a reliability-resiliencyadaptability framework that fits with the challenges of high-VIRE systems. It explicitly introduces electricity markets (and the volume cleared in these markets) as part of the broader optimization problem. Section 3 analyzes the main technical and market challenges associated with high VIRE in liberalized power systems. It also outlines practical examples from the U.S. and Europe. We find that although high-VIRE systems have technical challenges, these challenges can be likely addressed by a combination of strategies. Finally, Section 4 concludes with policy recommendations. 


\section{Reliability, Resiliency and Adaptability of Liberalized Power Systems}

This section discusses the reliability, resiliency, and adaptability (RRA) lexicon and then presents the RRA framework in more detail.

\subsection{Reliability and resiliency lexicon and the need for adaptability}

Reliable power systems consist of security (the dynamic response of the system to changes) and adequacy (the static existence of sufficient facilities to meet demand) (Billinton and Allan 2003; Zappa, Junginger, and van den Broek 2019). ${ }^{4}$ The value of electricity, referred to as the value of lost load (VOLL), is very high for many electricity consumers (Ovaere et al. 2019). Thus, an efficient power system with markets must balance supply and demand very reliably.

The terms "reliability" and "resiliency" have multiple competing definitions in the context of electric power systems (Billinton and Allan 1984; Kahnamouei, Bolandi, and Haghifam 2017; Phillips 2019; Plotnek and Slay 2021; Zappa, Junginger, and van den Broek 2019). One definition of reliability is a power system's ability to deliver electricity to consumers in the desired amounts (Zappa, Junginger, and van den Broek 2019). Reliability can be measured by the frequency, magnitude and duration of power outages (Hall, Ringlee, and Wood 1968).

The definition of resiliency has changed substantially over time (Plotnek and Slay 2021). To avoid overlap with the definition of reliability, we consider resiliency as the response to a disruptive event (Phillips 2019). In other words, it refers to the grid's ability to recover from an uncontrolled or cascading blackout or rolling blackouts. Resiliency is therefore measured as the time it takes to reduce the magnitude of power outages and return the system to normal operations. Although resiliency describes the experience after an outage, resiliency policies are, of course, set prior to outages.

We introduce the following reliability and resiliency variables:

$F_{y}$ : the frequency of power outages in year $y$;

$U_{v}$ : the average duration of power outages in year $y$, expressed in hours;

$S_{y}$ : the average magnitude of power outages in year $y$, expressed in megawatts.

Finally, power outages in year $y$ are defined by these three variables. The total shortage of electricity volume from the grid in year $y$ is calculated as $F_{v} U_{v} S_{v^{*}}$

We propose adding adaptability to the reliability and resiliency lexicon. Adaptability can account for actions that can mitigate the human and economic costs of outages as they occur, which can be substantial. One such action is rotating power outages so that the available power is spread broadly. Others include opening shelters to provide heat, cooling and other public safety functions and making back-up power supplies available. We use $A_{y}$ to denote the adaptability level in year $y$. We explicitly introduce the relation between the socioeconomic cost of power outages $\left(I_{y}\right)$ and adaptability efforts $\left(A_{y}\right)$. Finally, we extend the classical reliability-resiliency paradigm by suggesting that power systems should be analyzed within the RRA framework.

The RRA of a power system with markets also substantially depends on assets invested in or 
operated by non-market participants. In other words, it depends on economically regulated transmission and distribution companies and the system operator. ${ }^{5}$ These assets are critical to a power system's performance. In addition, adaptability depends on broader policies than those related to the power sector and other critical infrastructure. Furthermore, there are important physical, market and regulatory dynamics between these components that affect RRA, as we discuss below. For these reasons, markets alone cannot ensure an efficient level of RRA.

The RRA of a power system can be decomposed into sequences of events that lead to power outages. ${ }^{6}$ Such a sequence has an initiating event, such as the failure of a generation unit or extremely cold weather. This event may then lead to other equipment failures or changes in system conditions, such as a load amount that cannot be entirely served. The sequence ends in one of three mutually exclusive power system states:

1. All firm load is provided electricity.

2. Some firm load is provided electricity, and other firm load is disconnected in a controlled manner to balance supply and demand (i.e., a rolling blackout).

3. Firm load is disconnected in an uncontrolled manner (i.e., a blackout). ${ }^{7}$

At their core, RRA calculations identify, characterize and aggregate these sequences to quantify their impacts on the frequency, magnitude, duration of power outages, and their associated socioeconomic costs (which depend on the adaptability level).

The combination of these sequences determines the grid's reliability. Multiple analytical frameworks for reliability can be used to perform these calculations, and one that has been applied to power systems is probabilistic risk assessment (Felder 2001).

The many sequences that lead to power outages can be grouped into two categories based on whether their initiating events are independent or dependent failures (Felder 2001). ${ }^{8}$ Independent failures are more common than dependent ones but have smaller impacts on a power system's reliability. Dependent failures include severe weather, fuel delivery system failure, a failure of the monitoring and controlling system and malicious actions. Because power systems are highly reliable by design, multiple component failures are typically needed for a power outage to occur.

A complete RRA analytical framework for a power system within a market includes six steps. First, it identifies and traces all of the sequences that may result in power outages above a certain probability level owing to independent or dependent failures. Second, it considers both market and non-market failures. Third, it evaluates the market's ability to clear supply and demand in probabilistic terms. In other words, it does not assume that the market performs this function perfectly reliably. A pricing mechanism is helpful in this regard by providing incentives for increasing supply and decreasing demand. Fourth, the probability of each event in the outage sequence is estimated based on data. Fifth, the costs and benefits of changing the probabilities of outage sequences across the entire electricity supply chain are assessed. Sixth, the framework provides input into the evaluation of RRA policies so that tradeoffs can be made among the three measures, including accounting for uncertainty.

The frequency, magnitude and duration of blackouts are associated with both economic and social costs (Matthewman and Byrd 2014). The economic cost, the VOLL, is not simply dollars per megawatthour 
(MWh) but is a function of all three variables. It can be reduced through adaptability. Additionally, blackouts incur social costs, such as lost human lives, that may be quantified in dollar terms but may be more appropriate to track separately to avoid reducing them to a mere dollar figure. Moreover, the VOLL varies by customer type, whether customers are notified, the time between a notification and an outage, and outage length (Joskow 2006c; Ovaere et al. 2019). Thus, the VOLL (denoted $I_{y}$ ) can be considered a tensor whose numerical value varies along multiple dimensions:

$$
I_{y}=\text { function }\left(F_{y}, U_{y}, S_{y}, A_{y}\right) .
$$

Finally, the variable and intermittent nature of renewable energy increases the need for a clear RRA framework.

\subsection{RRA framework for liberalized power systems with high VIRE}

The performance of liberalized power systems with high or ultra-high VIRE depends on technical and market challenges, including the market clearing mechanism's reliability. It also depends on transmission and distribution (which are economically regulated and not market based), markets (including missing or incomplete markets) beyond the electric power system, such as fuel delivery, and resiliency and adaptability policies made by policymakers.

We propose an original formalization of this framework based on welfare maximization with respect to RRA variables. Our mathematical framework therefore defines the optimal RRA levels as the starting point for policies. In contrast, the standard framework considers physical variables (i.e., capacity and energy) ${ }^{9}$ and takes the loss of load probability (LOLP) as an input. Our approach maximizes the total welfare from the electricity sector. This welfare is estimated as the social benefit of electricity consumption less the social cost of outages and the total cost of generating and transporting electricity.

The social benefit of electricity consumption consists of two components. The first is the utility $(V)$ of consuming electricity from the grid. This utility is adjusted by the market's ability to clear and the availability of physical assets. The second is the utility $(W)$ of consuming self-generated electricity in the case of a shortage of electricity from the grid. This latter component relates to the power system's adaptability. Quantifying the utility of electricity consumption is key to solving the RRA framework. This utility may vary among consumers and by the origin of the electricity (i.e., from the grid or self-produced). The additional social costs of blackouts are costs that are not reflected in the benefits of consuming electricity, which partly depend on adaptability policies.

The objective function of the RRA framework is also constrained by the physics of power systems. It must balance the demand and supply (constraint $2 \mathrm{~b}$ ) and respect the physical laws of the network (constraint 3d). Unserved energy, denoted as $E N S_{h, y}$, may be due to price rationing (i.e., the market does not clear) or non-price rationing. The effect of market clearing is explicitly introduced in constraint 2c. We distinguish between the volume of electricity resulting from the market clearing $\left(\pi_{h, y}^{M}\right)$ and the volume resulting from the system operator's out-of-market actions $\left(\pi_{h, y}^{R}\right)$.

In addition to considering the time dimension (years $y \in Y$ ), the problem should be solved by considering numerous relevant operational scenarios in each year $y$. Each scenario should 
embed not only weather assumptions but also a combination of critical events in the grid or generation units. This concept is known as "critical network element and contingency" in the European lexicon, as defined by ENTSOE (2018). Operational and planning policies can then be derived from the optimal solution $F_{y}, U_{y}, S_{y}, A_{y}$ to ease practical implementation. In practice, these policies then affect investments in infrastructure and the associated capital, maintenance and operational costs. They may also impose constraints on operations, such as operating reserve requirements.

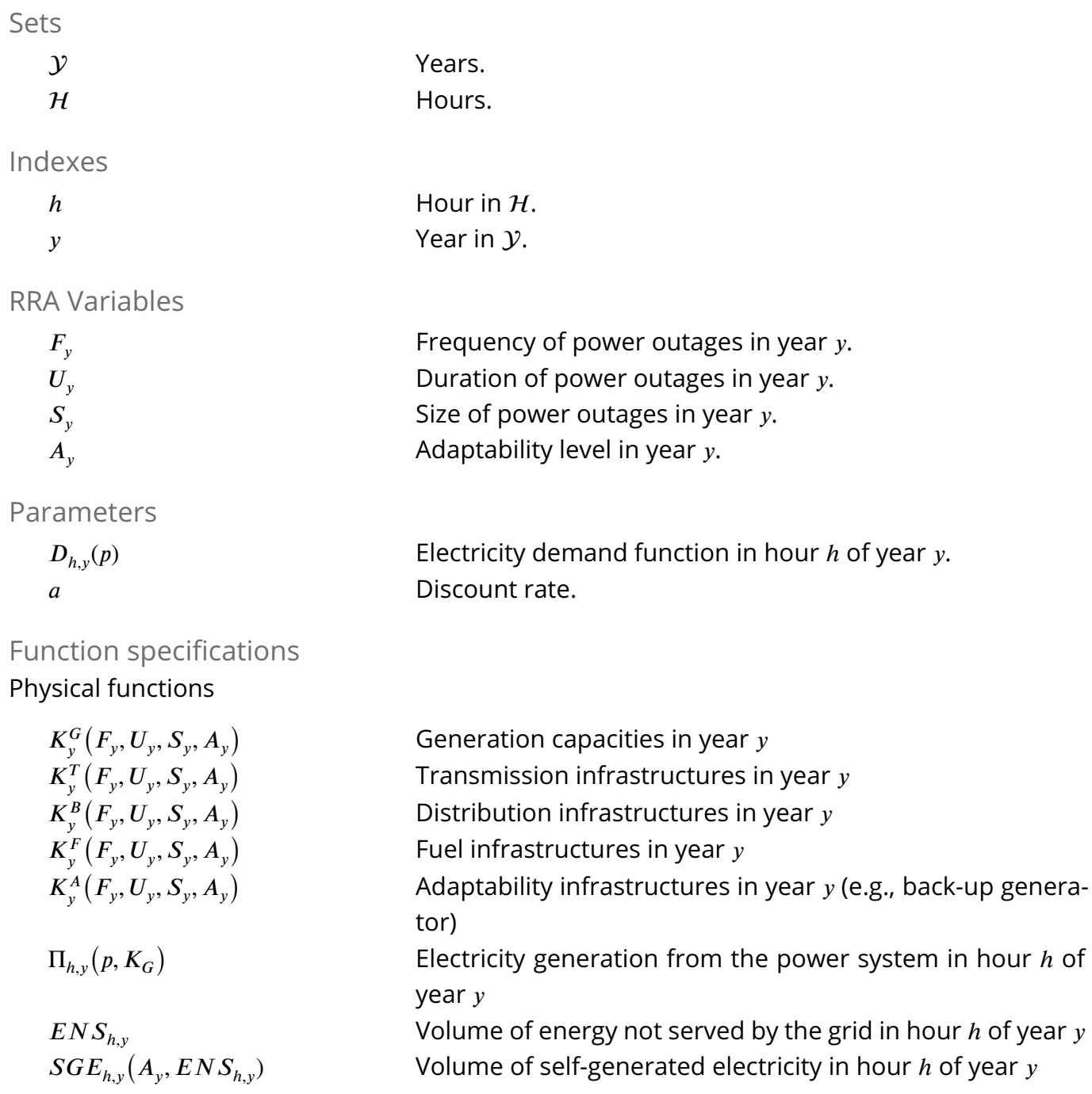

Function specifications Physical functions

$K_{y}^{G}\left(F_{y}, U_{y}, S_{y}, A_{y}\right)$

Generation capacities in year $y$

$K_{y}^{T}\left(F_{y}, U_{y}, S_{y}, A_{y}\right)$

Transmission infrastructures in year $y$

$K_{y}^{B}\left(F_{y}, U_{y}, S_{y}, A_{y}\right)$

Distribution infrastructures in year $y$

$K_{y}^{F}\left(F_{y}, U_{y}, S_{y}, A_{y}\right)$

Fuel infrastructures in year $y$

$K_{y}^{A}\left(F_{y}, U_{y}, S_{y}, A_{y}\right)$

$\Pi_{h, y}\left(p, K_{G}\right)$

Adaptability infrastructures in year $y$ (e.g., back-up generator)

Electricity generation from the power system in hour $h$ of year $y$

EN $S_{h, y}$ Volume of energy not served by the grid in hour $h$ of year $y$ $S G E_{h, y}\left(A_{y}, E N S_{h, y}\right)$ Volume of self-generated electricity in hour $h$ of year $y$ 


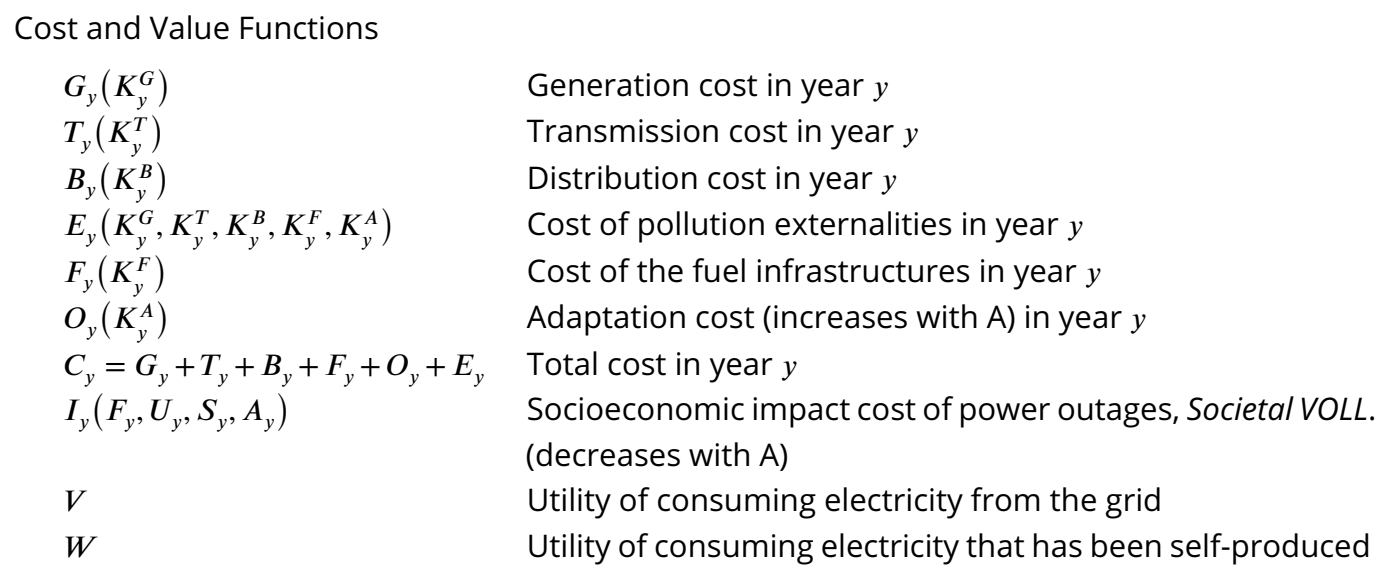

Other functions

$\begin{array}{ll}\Pi_{h, y}^{M} & \text { Quantity of electricity cleared in the market in hour } h \text { of } \\ & \text { year } y \\ \Pi_{h, y}^{R} & \text { Additional quantity of electricity produced thanks to sys- } \\ & \text { tem operator's actions in hour } h \text { of year } y .\end{array}$

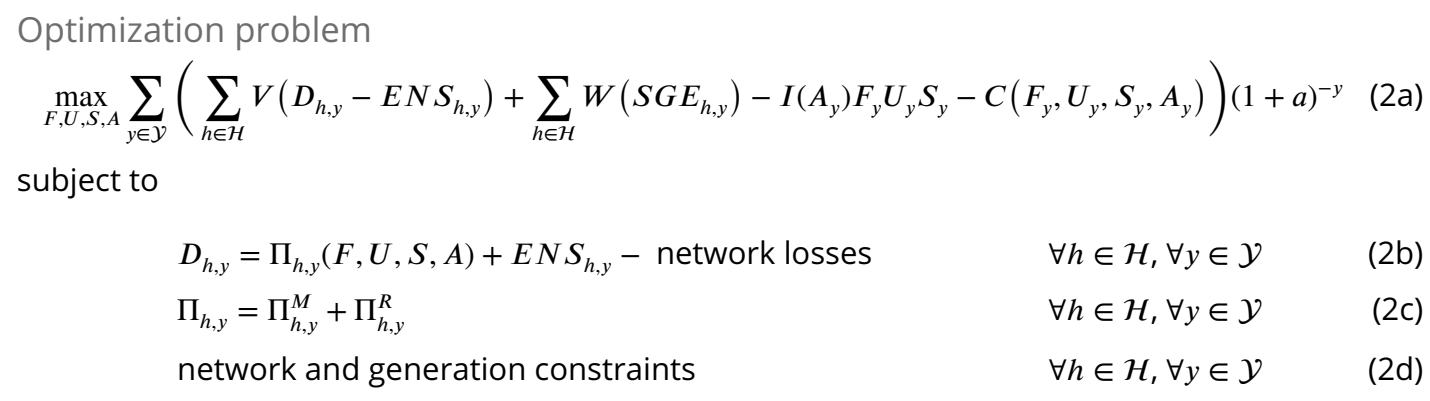

By analyzing this model, we obtain the following results. First, the first-order conditions show that the marginal benefit of investing an additional dollar in reliability, resiliency or adaptability is the same at the optimum. This result is subject to a binding constraint. Second, this same result applies to incremental improvements in specific infrastructure categories (e.g., generation, transmission or distribution, as well as the market clearing mechanism, operational restrictions and other policy choices. Third, the market mechanism is just one way to ensure the reliability of the system. Finally, the reliability effects of ultra-high VIRE (or any investment decisions) involve complex interactions with other decision variables, benefits of consuming electricity, costs, and policy decisions. 


\section{Technical and Market Challenges in Liberalized Power Systems With High VIRE}

E lectricity markets constitute a key element of the reliability, resiliency, and adaptability optimization framework of power systems (see section 2), and renewables may bring new challenges to the functioning of electricity markets. This section discusses the technical and market challenges associated with high VIRE in liberalized power systems based upon practical examples from the U.S. and European power systems. These challenges are directly related to the RRA framework described in the previous section. Subsection 3.1 reviews technical solutions that allow power systems with high or ultra-high VIRE to operate in practice. Then, subsection 3.2 shows that liberalized wholesale electricity markets can handle VIRE with zero or near-zero variable costs.

\subsection{Technical feasibility of high-VIRE power systems}

VIRE sources introduce technical challenges in balancing supply with demand because their output is non-dispatchable and intermittent (Heard et al. 2017). In the RRA framework (see section 2), operational policies handle balancing issues by implementing appropriate rules such that the technical requirements to balance the system are met. However, this process can be carried out only if technical solutions to balance supply with demand exist in high-VIRE power systems. We discuss such solutions in this subsection.

Importantly, some renewable energy resources, such as hydroelectric facilities, biomass, biofuel, geothermal and concentrating solar power, are dispatchable. In many cases, however, their availability depends on local conditions (Tran and Smith 2017; Zappa, Junginger, and van den Broek 2019). In addition, new energy storage technologies that can supply energy from milliseconds to hours are decreasing in cost and providing multiple services (Elshurafa 2020). Thus, the development of $100 \%$ renewable energy systems does not necessarily require $100 \%$ VIRE or even ultra-high VIRE. This point is sometimes lost when the qualifier "variable" is omitted from the discussion.

Many non-mutually exclusive solutions to address these features of VIRE are available. They include geographic diversity in VIRE; improved VIRE forecasting; energy storage, including electric vehicles; VIRE curtailment and active control; electrical load control; and transmission enhancements. Others are synchronous condensers, enhancing joint operations with neighboring power systems, districting heating and cooling, heat pumps and smart meters. Information and communication technology solutions and improved market designs are also available (Brown et al. 2018; Kroposki 2017; Paiho et al. 2018; Papaefthymiou and Dragoon 2016).

Currently, empirical evidence on the reliability of ultra-high or $100 \%$ VIRE grids is based on small islands given that large-scale grids are only at the starting phase of this transition (Heard et al. 2017), and the transition will take time. Moreover, creating a $100 \%$ or ultra-high renewable power system is not a one-time decision. Instead, it is a series of continual decisions made from a starting point of a relatively low percentage of renewables. Even under aggressive policies, this percentage would likely change slowly over several decades. Thus, policymakers can develop multiple strategies over the long term to learn from the experience accumulated during this transition. They can then adjust their policies accordingly (Anandarajah et al. 2009). Their goals may be reconsidered if, as renewable penetration increases, costs 


\section{Technical and Market Challenges in Liberalized Power Systems With High VIRE}

unexpectedly rise or reliability problems emerge. Thus, policymakers have a credible exit strategy from pursuing an ultra-high or $100 \%$ renewable grid. The option to delay or stop the transition if necessary should be kept available.

For these reasons, some analysts find that the transition to ultra-high or $100 \%$ VIRE is potentially feasible, although perhaps costly, if pursued in conjunction with research and development, institutional changes and relevant policies (Papaefthymiou and Dragoon 2016; Zappa, Junginger, and van den Broek 2019). That being said, it is important not to minimize the difficulty or even assume the possibility of this transition (Abbott and Cohen 2019; Heard et al. 2017).

In summary, although VIRE does create challenges for reliability, many renewable energy resources and low-carbon or non-carbon-emitting resources are not intermittent. Many non-mutually exclusive strategies can address variability and intermittency. Policies can be adopted with attenuating costs, including phasing in VIRE, to help evaluate and respond to any associated reliability challenges.

\subsection{Wholesale electricity markets with high VIRE}

When combined with other policies, wholesale electricity markets can be a means of improving the power sector's efficiency while maintaining reliability (Hogan 2014). Properly designed wholesale markets must account for electricity's unique physical properties (Felder 2020). ${ }^{10} \mathrm{~A}$ wholesale electricity market must balance supply and demand instantaneously within narrow limits to avoid power outages. ${ }^{11}$ This property is particularly relevant to whether VIRE is incompatible with electricity markets. Supply has to equal demand to prevent cascading outages. Supply and demand can be balanced either through a market clearing mechanism or by disconnecting electrical load (i.e., implementing rolling blackouts) following a non-price rationing scheme.

This property is unique to the electricity market. In other markets, if a supply shortage occurs, only incremental consumers cannot purchase the desired good or service (Jaffe and Felder 1996). Although both excess supply and excess demand cause reliability concerns, excess demand is the more practical concern. Excess supply can be addressed by turning off running generation and lowering prices to increase demand. ${ }^{12}$

In this section, we analyze the functioning of wholesale electricity markets with high VIRE across different key axes. First, we consider the reliability of a wholesale market's price-clearing mechanism (subsection 3.2.1). Then, we investigate the pricing mechanism with zero or near-zero variable costs (subsection 3.2.2). Finally, we examine the issues introduced by additional mechanisms for adequacy and VIRE developments (subsection 3.2.3).

\subsubsection{Market clearing}

Markets, including that for electricity, do not always clear (Jaffe and Felder 1996; Joskow 2006c). The electricity market clearing mechanism consists of collecting and providing information; economic incentives, including payment likelihood; and algorithms implemented via software to calculate associated prices. Although this mechanism is not physical, it can be analyzed from a reliability perspective as if it were. Our analysis assumes that sufficient balancing services are available to successfully transition the power system from a shortage to equilibrated supply and demand. In other words, we assume that the power system can reliably transition from one state to another. ${ }^{13}$ 
In the subsequent section, we evaluate whether the resulting price is efficient.

In liberalized U.S. electricity markets, regional transmission operators (RTOs) have access to wholesale loads' bids and generators' offers. These markets include both a day-ahead market and a real-time market. The day-ahead market clears every hour based on day-ahead bids and offers. The real-time market clears every five minutes based on physical demand, offers, generation, transmission and reliability constraints. In the real-time market, the load is a price taker and cannot be physically prevented from consuming electricity. This constraint may be modified with technology and associated policies. The system operator can run an intra-day unit commitment in response to major changes in the system that depart from the day-ahead unit commitment's assumptions. Note that real-time prices are posted after the fact (Zheng et al. 2010). Thus, the load does not know the real-time price at the time of purchase, which is also the time of consumption. ${ }^{14}$

In Europe, transmission system operators (TSOs) and power exchanges (PXs) are distinct entities. Unlike in the U.S., European TSOs do not have direct access to wholesale market bids, and they only operate the balancing market. They provide network parameters to PXs to be considered in the zonal market clearing in step 1 of Table 1. These parameters are either the available transfer capacities between countries or the power transfer distribution factors matrix when the flow-based method is used. The European wholesale day-ahead market clears only once for the 24-hourly products in a given day, with an implicit network capacity allocation. TSOs can modify generators' dispatch programs if network congestion occurs, but the re-dispatching volume has been relatively limited in most European countries..$^{15}$ The intraday markets are a combination of continuous and auction trading and end at least 15 minutes before the products are due for delivery.
Whether sequences of events that result in demand exceeding supply can be prevented from resulting in a blackout depends on several factors. These factors are the frequency, magnitude and duration of the shortfall and the probability that market mechanisms can resolve the shortfall via prices (step 1 of Table 1). The latter depends on whether the market mechanism works, particularly if binding price caps to limit the exercise of market power or price gouging exist. It also depends on whether sufficient political will exists to enforce very high prices. Finally, it can depend on whether the problem is so severe that it is no longer socially acceptable to use markets to resolve it.

For the real-time market to clear, price responsiveness must be sufficient given the level of supply. The load must respond, that is, it must decrease its consumption sufficiently in terms of the amount, time and location. The load must also be liable to pay potentially very high prices, which requires a highly reliable credit policy and non-intervention by the political process (Joskow 2006c). ${ }^{16}$

Furthermore, these market descriptions assume that the prior submission of bids reflects actual welfare preferences in real time (Leslie et al. 2020), which may not hold, particularly when the power system's reliability is threatened. Due to the physical property mentioned previously, system operators may prematurely intervene in the market to ensure that this assumption holds. This action may reduce prices, thereby undercutting the pricing mechanism to preserve reliability (Joskow 2006c; Mays 2021). Table 1 summarizes the sequence of events that must occur for the market clearing mechanism to operate properly. 
Table 1. Sequence of events that must occur for the market clearing mechanism to work.

1. The market clearing mechanism correctly calculates the necessary price to clear the market based upon inputs from generators, load and the system operator.

2. The necessary balancing services to transition from the current state to the market clearing state are available.

3. The system operator does not prematurely implement rolling blackouts before the market clearing mechanism responds.

4. The load knows the real-time price that it will pay, either by being informed ahead of time or by accurately determining the price.

5. The load serving entities that pay the real-time price are required to do so (i.e., they have posted sufficient credit).

6. The payment of (presumably very high) real-time prices is enforced by the political process.

Source: Authors.

It is analytically difficult to estimate the probability that the sequence in Table 1 occurs. The challenge with taking an empirical approach is that large supply shortfalls do not occur frequently enough to make accurate estimates. Likewise, it is difficult to estimate the probability that any individual step occurs. Methods to test whether a step will occur and assess its probability of occurring have not been developed.

Figure 1 presents the different situations that may occur during market clearing. We assume that situations 1 to 4 are mutually exclusive. $P_{i}$ denotes the probability that situation $i(i \in\{1 ; 2 ; 3 ; 4\})$ occurs. In each situation, $P_{\bar{m}, 1}$ is the probability that the market does not clear. Situation 1 corresponds to the classical situation in which demand and supply intersect and the market always clears. Thus, $P_{\bar{m}, 1}$ is zero. In situation 2, the market clears, but a rule is required to define the price, as the price levels for demand and supply are different. In situations 3 and 4, no market clearing solution exists. In situation 3 , demand exceeds supply in the market. In situation 4 , the prices in the demand and supply offers are mismatched. Thus, $P_{\bar{m}, 3}$ and $P_{\bar{m}, 4}$ are equal to one. Situations 3 and 4 correspond to the non-price rationing of electricity demand via a rolling blackout. 
Figure 1. The four mutually exclusive market situations.

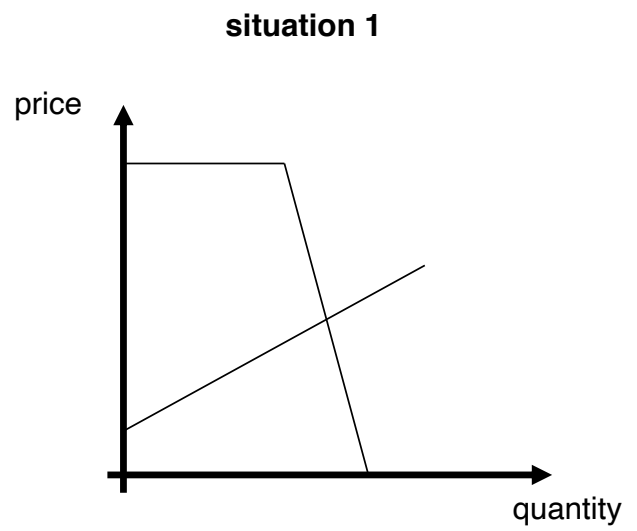

Classical situation

- The market clears. situation 2

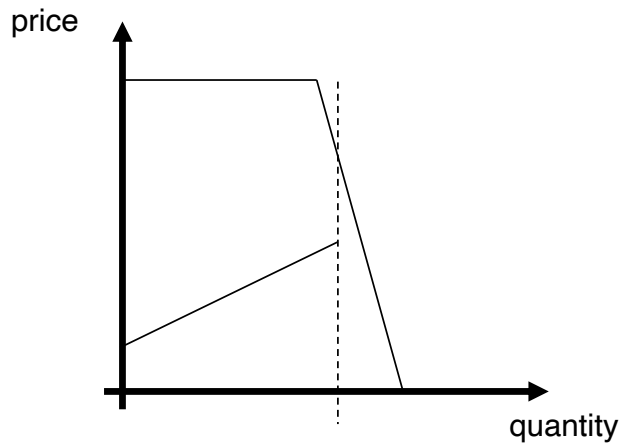

Demand and supply match at different price levels.

- The market clears.

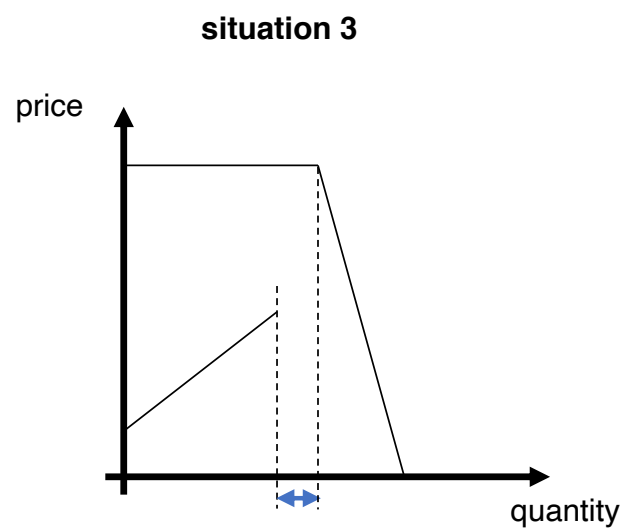

Demand exceeds supply in the market.

- No market clearing solution.

- Non-price rationing (rolling blackout). situation 4

price

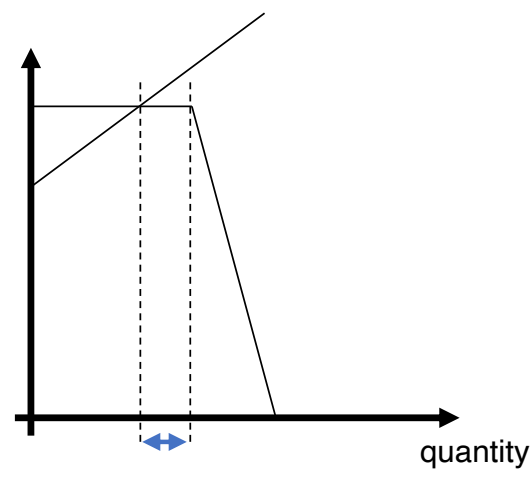

Enough supply but mismatch in prices.

- No market clearing solution.

- Non-price rationing (rolling blackout).

Source: Authors. 


\subsubsection{Efficient pricing with zero or near-zero marginal costs}

Whereas the previous subsection discussed the market clearing mechanism in the context of reliability, this section does so in the context of efficient prices. A fundamental assumption is that the loads whose electricity is most valued by society are also willing and able to pay extremely high electricity prices during supply shortages. This assumption may not hold because equity concerns may override allocative efficiency if electricity is considered a merit good (Dilnot and Helm 1987)..$^{17}$

Economic literature of peak load pricing finds that prices rise so that markets clear and suppliers cover their costs exactly. This finding also holds in some cases of stochastic demand and supply (Boiteux 1949, 1960; Crew, Fernando, and Kleindorfer 1995). Many studies reach similar findings regarding the application to electricity markets (Joskow [2006c] and the references therein).

Under some simplifications, the optimal generation mix can be inferred using the classical screening curves method (Green 2005). This method can ensure a specified LOLP and cost recovery for all generation units. In efficient wholesale electricity markets, the optimal generation mix (baseload, intermediate and peaking) is installed. For a few hours a year, the supply curve does not intersect the demand curve. In that case, the price rises to the VOLL, per Equation (3) (Cretì and Fontini 2019; Léautier 2019).

$$
L O L P^{*}=\frac{h R C}{V O L L-c}
$$

The hourly rental cost of capacity (hRC) and the VOLL are in units of tens of thousands of dollars per $\mathrm{MWh}$. The marginal cost of the marginal generator, c, is in units of dollars per MWh. Thus, the value of $c$ is practically irrelevant in determining LOLP*. As per Equation (3), the optimal LOLP* changes if the VOLL based on consumers' preferences varies. It also changes if the peaking technology, to which $\mathrm{hRC}$ and $\mathrm{c}$ refer, changes.

As Equation (3) shows, low- or zero-marginalcost resources do not materially affect LOLP*. Furthermore, energy sources with low marginal costs compared to total costs are not new to wholesale electricity markets (Joskow 2006c; Leslie et al. 2020; U.S. EIA 2021). Hydroelectric and nuclear power plants are examples of such sources. Additionally, the intermittent nature of technologies does not impact the optimal LOLP* as defined in Equation (3) if the peaking technology remains the same. In this case, VIRE may only affect the volume of electricity that is not served by changing the shape of the residual load curve. However, the optimal LOLP* is different for a $100 \%$ VIRE system with no thermal peaking units. In this case, it depends on the power system's characteristics (e.g., storage assets and smart home technologies for controlling electricity uses). This formula also works if wholesale prices are negative. ${ }^{18}$

The LOLP is not a probability measure of the loss of load. Instead, it measures the probability of demand exceeding supply. The actual effect of demand exceeding supply depends on several factors. Thus, the standard LOLP formula (Equation [3]) should be revisited in the context of electricity markets and adaptability. First, the classical approach focuses on demand exceeding supply but does not explicitly consider the market clearing mechanism. Thus, it should be extended to consider the probability of the market not clearing when rolling blackouts are necessary. Second, when demand exceeds supply, consumers may use their own adaptability equipment (e.g., self-generators or home insulation) 
to reduce the effects of the situation.

In practical terms, we consider the four mutually exclusive situations shown in Figure 1. The probability of a reliable situation (denoted $P$ ) corresponds to Equation (4). $P_{B, i}$ denotes the probability that a pure blackout occurs in situation i. $P_{R, i}$ is the probability of non-price rationing and a rolling blackout in situation $i$. In this context, Equation (3) reflects the situation with no blackouts owing to a lack of physical capacities and no rolling blackouts owing to non-price rationing.

$$
P=\sum_{i=1}^{4} P_{i}\left(1-P_{R, i}\right)\left(1-P_{B, i}\right)
$$

As we explain in subsection 2.3.1, rolling blackouts are required in situations 3 and 4 because no market clearing solution (i.e., non-price rationing) exists. Thus, $P_{R, 3}$ and $P_{R, 4}$ equal one. In situations 1 and 2, the market clears $\left(P_{R, 1}=0\right.$ and $\left.P_{R, 2}=0\right)$, but a blackout can still occur due to real-time technical issues. Finally, Equation (4) becomes:

$$
P=P_{1}\left(1-P_{B, 1}\right)+P_{2}\left(1-P_{B, 2}\right)
$$

Equation (5) shows that reliability depends on both the probability of a blackout and the probability of situations 1 and 2 occurring. The classical analysis does not consider this term.

Even without storage, which can mitigate near-zero or zero prices, the presence of elastic demand raises prices above low levels (Leslie et al. 2020). Thus, with a sufficiently sloping demand curve, wholesale prices can efficiently balance supply and demand. Then, at the optimal level of generation investment, total costs can be recovered. This outcome holds even if the marginal unit's marginal cost is below its total cost..$^{19}$ Thus, efficiency depends on the probability that the market clearing mechanism is successful and the level of the VOLL.

The VOLL is set via a regulatory process and, thus, is determined for practical purposes months, if not years, before an actual shortage situation. Thus, it may be set too high or too low rather than optimally. If it is too low, then some electricity demand will be unserved, incurring an associated economic loss. If it is too high, then prices set using the VOLL will be too high, although the frequency and duration of such situations would be lower than if the VOLL were set below the true VOLL.

Finally, market inefficiency is not due to the zero-marginal cost or the intermittency of renewables but could arise because of unexpected interactions between efficient market pricing and out-of-market mechanisms (Felder 2011). When the energy price falls to zero, economically VIRE generators with almost zero variable cost are indifferent between being dispatched or not. However, out-of-market mechanisms that provide additional remuneration based on the volume of electricity effectively injected to the grid introduce distortions and competition among generators to be dispatched even when zero or negative prices arise.

\subsubsection{Capacity requirements and market-based renewable remuneration methods}

Capacity requirements and other specific mechanisms to foster VIRE development are widespread in the U.S. and Europe. These mechanisms may take various forms (see Figure 2). They can be categorized as quantity or price based and centralized or decentralized. Capacity mechanisms can be classified as targeted or capacity-wide mechanisms. Support mechanisms can be classified as technology-neutral or technology-specific mechanisms. 
Figure 2. Overview of adjustments or additional mechanisms in liberalized power systems.

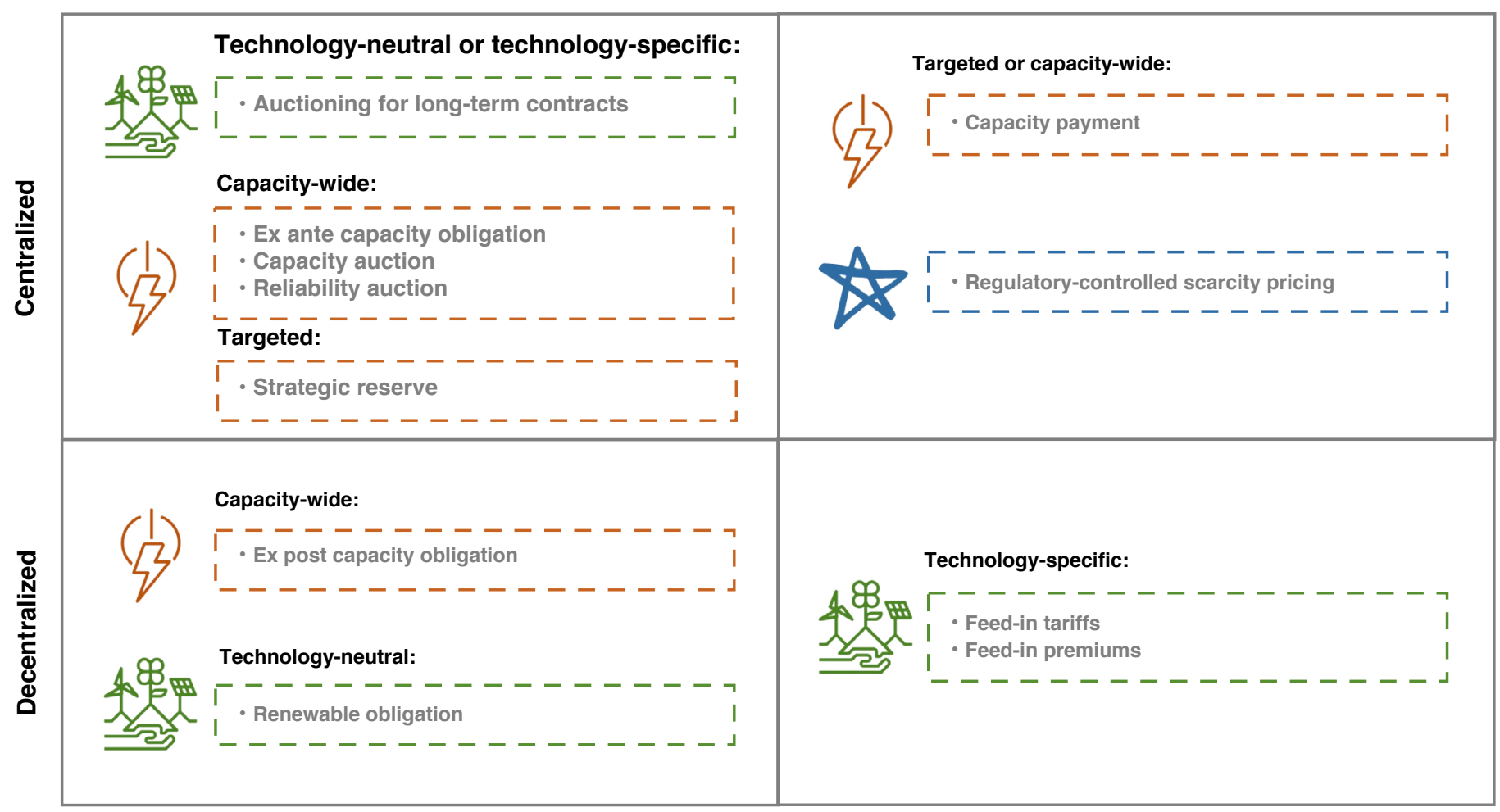

Quantity-based Price-based

Adjustments of the energy-only model.
Additional mechanisms to address resource adequacy.
Additional mechanisms to address renewables development.

Source: Petitet et al. (2021).

In the U.S., capacity requirements are used to achieve prescribed resource adequacy levels in wholesale electricity markets (Jaffe and Felder 1996). Load-serving entities are required to purchase sufficient capacity to cover their peak loads during system peaks plus a stipulated reserve margin calculated to achieve a desired LOLP.

Renewable portfolio standards (RPS) are analogous to capacity markets in that a minimum quantity of renewables is required based on the retail load. This requirement can be satisfied via a market mechanism of buying and selling renewable energy credits. In RTO markets, RPS are set by states, whereas the federal government regulates capacity markets. A forward clean energy market (FCEM) consolidates RPS from multiple jurisdictions into a single market, which may be under federal jurisdiction. ${ }^{20}$ RPS and the FCEM are separate from capacity markets. In contrast, an integrated clean capacity market (ICCM) is designed to combine a wholesale market's capacity remuneration mechanism with a market-like renewables mandate (Spees et al. 2021). Collectively, these approaches are referred to as market-based renewable market standards. 
The EU Emission Trading System introduced in 2005 has not triggered sufficient investments in VIRE in Europe (Brohé and Burniaux 2015; Löfgren et al. 2014). Renewables targets for European countries were introduced in Directive 2009/28 EC. To foster more investments in renewable technologies and reach these targets, most European countries implemented feed-in tariffs or other support schemes. However, because of the European Commission's state aids guidelines issued in 2014 (European Commission 2014), European countries have progressively switched to feed-in premiums (Boasson 2021). Although feed-in premiums are focused on the investment side, most European countries have implemented 'guarantees of origin' mechanisms to allow suppliers to propose green electricity to end consumers. Unlike in the U.S., however, RPS have never become the prevailing mechanism in Europe.

Abstracting from the differences among these VIRE mechanisms, we can draw the following conclusions related to reliability and efficiency. First, these renewable mechanisms do not specify the necessary balancing services to achieve the reliability requirements of a bulk power system. Transitioning the power system from one reliable state to the next requires balancing services, given that demand and supply can change across timesteps of fractions of a second to days. If the VIRE mechanisms did include flexibility requirements, they could conceivably provide the needed services. ${ }^{21}$

However, VIRE may require a more expansive set of balancing services than the current set of ancillary services (Karbouj et al. 2019). ${ }^{22}$ The mechanical inertia of rotating turbines provides stability to the power system through the generation of electricity (Johnson, Rhodes, and Webber 2020; Karbouj et al. 2019). With large amounts of VIRE, the ramping capabilities of traditional operating reserves (i.e., ten-minute spinning, ten-minute non-spinning and thirty-minute reserves) may need to increase. Additional types of reserves, such as reserve resources that are available across longer times, may be needed (EU-SysFlex 2018). Future flexibility needs will depend not only on VIRE penetration but also on renewable technologies and the spatial characteristics of power systems (Koltsaklis, Dagoumas, and Panapakidis 2017). Coordination between wholesale reserve markets may be a solution for enhancing efficiency in power systems with high VIRE shares (Van den Bergh and Delarue 2020).

In the U.S., mandates on renewables may increase or decrease social welfare. Furthermore, they are unlikely to be socially optimal from a welfare perspective. The RPS and the FCEMs administered by states sever the link between investments in renewables and wholesale prices. Under these mechanisms, levels of renewable investments are set politically and not by wholesale market prices. The out-of-wholesale-market payment mechanism for renewables, as is the case in RPS, is designed to set the revenue per MWh of an applicable renewable resource to cover any revenue shortfalls that occur from the wholesale market. ${ }^{23}$

The RPS and state-administered FCEMs make capacity investment decisions for the applicable renewable resources an open (political) loop. In contrast, other generation resources depend on revenues from wholesale markets to recoup their total costs. These mechanisms also shift some of the investment risk to ratepayers from developers. With the ICCM, the renewable requirements are set by the federal regulator and are integrated with resource adequacy requirements. Given those requirements, capacity, energy and ancillary services' revenues are (theoretically) internally 
consistent. Thus, whether high or ultra-high VIRE electricity markets are efficient depends on how renewables are renumerated and not on their variability, intermittency or near-zero marginal costs.

This discussion regarding non-optimal social welfare and open-loop VIRE deployment also applies to the
European context. Indeed, feed-in premiums and political VIRE goals lead to renewables development that is unlikely to deliver the optimal VIRE share or the optimal social welfare. Furthermore, the detailed rules of feed-in premiums are key to the successful or unsuccessful integration of VIRE in power systems. 


\section{Conclusions and Policy Implications}

$\mathrm{M}$ arkets with ultra-high or $100 \%$ renewables can be both reliable and efficient if an integrated approach of RRA analysis and market mechanisms is used. This paper provides a conceptual framework for wholesale electricity markets as a policy option to implementing ultra-high renewable energy. This framework should therefore be adopted for policy analysis.

Several key policy implications can be drawn from this analysis. First, the reliability and resiliency of electricity markets cannot be analyzed in isolation. Instead, they must be considered in the complete context of the entire power system supply chain and adaptability policies outside the sector. Policymakers should integrate reliability, resiliency, and adaptability policies by starting with an integrated analytical framework, such as that proposed in this paper.

Second, the frequency, magnitude and duration of outages are the fundamental pieces of reliability and resiliency policy analysis. These three characteristics are needed to appropriately describe the VOLL. Thus, the VOLL may not be interpreted as a simple number but as the result of, at least, these attributes (tensor). The VOLL may not capture some additional costs to society that should be considered and incorporated into policies. Thus, policymakers should revisit the definition of the VOLL in their analyses and proposals.

Third, the classical LOLP is a useful but incomplete measure of the reliability of wholesale electricity markets. Policymakers evaluating the role of electricity markets in achieving their goals should further distinguish between the different situations currently aggregated within the LOLP metric. Electricity markets should be subject to reliability analyses so that efficient, effective policies can improve their performance in avoiding rolling and cascading blackouts.
Fourth, many technical options are available to achieve the goal of ultra-high levels of renewables. Markets can be modified to achieve this renewable energy policy goal, and in-market mechanisms are preferred to out-of-market mechanisms. Policymakers can learn over time to craft policies that cost-effectively and efficiently provide sufficient balancing resources to increase VIRE levels. This approach may be more effective than committing to specific VIRE mandates without the benefit of learning from experience.

Fifth, the reliability and efficiency of electricity markets with high or ultra-high VIRE levels depend on how renewables are renumerated. Policymakers should consider the reliability and efficiency implications of funding VIRE outside of wholesale electricity markets and without providing incentives for VIRE to provide the balancing services and flexibility that will be increasingly required as their penetration levels rise. 


\section{Endnotes}

A state energy regulator told one of the authors that a particular renewable funding mechanism was adopted to hide electricity bills' costs from end users.

2 Wind and solar both have variable energy outputs. Their output may change in predictable ways, as when the sun rises and sets, and in unpredictable ways (intermittent), as when local cloud cover changes. Thus, they should be characterized as variable and intermittent. They are also referred to as non-synchronous renewable energy resources (Johnson, Rhodes, and Webber 2020) and variable renewable energy resources (Zappa, Junginger, and van den Broek 2019).

${ }^{3}$ They find that this result only applies to liberalized markets and not to centrally planned systems. Moreover, this situation may not hold for renewables that are not variable or do not have zero marginal costs.

${ }^{4}$ Many interchangeable terms refer to generation adequacy, including "supply security," "reliability," "resource adequacy" and "supply diversity" (Joskow 2006c).

${ }^{5}$ The system operator may be a regional transmission operator and an independent system operator or a transmission system operator.

${ }^{6}$ One such decomposition considers every possible state of every possible component in the power system. This decomposition encompasses all possible mutually exclusive states.

${ }^{7}$ Blackouts are unplanned disruptions of electricity service to multiple customers that last more than five minutes (Hines, Apt, and Talukdar 2009). Uncontrolled or cascading blackouts occur when the power system operator has lost control of the grid. In this situation, generation and transmission facilities automatically disconnect from the grid to protect personnel and equipment so that it is available to restore power at the appropriate time. Rolling blackouts are controlled interruptions of power to loads. In short, rolling and uncontrolled blackouts implement non-price rationing (Joskow 2006c), which is less efficient than price-based approaches (De Nooij, Lieshout, and Koopmans 2009).

8 "The term common cause failure is related to failure event whose occurrence implicates failures of two or multiple components, occurring simultaneously or nearly so, and which are a direct consequence of a shared cause" (Kančev and Čepin 2011, 1).

${ }^{9}$ This problem can be translated into an equivalent problem with physical variables: generation, transmission, the distribution and fuel infrastructures and the adaptability level.

${ }^{10}$ The term "free market" is vague and carries numerous connotations. Here, the term "designed market" is used to mean a government policy creating a market that would not otherwise exist. This concept contrasts with most markets, which are developed informally or formally through non-government efforts.

11 In addition, the loop flow must be efficiently priced in electricity markets. Electricity on a meshed network moves along multiple paths and affects the flows on all other paths. Thus, a mechanism is needed to account for positive and negative externalities so that the transmission network may be cost-effectively utilized without jeopardizing reliability.

${ }^{12}$ This process includes VIRE, although policymakers have been reluctant to curtail renewable resources when other options are available (Pollitt and Anaya 2016). 
${ }^{13}$ In practice, this is not the case, but the probability of this assumption could be evaluated and incorporated into the overall reliability analysis.

${ }^{14}$ In some cases, system operators may have to calculate prices owing to missing data or revise prices after the fact.

${ }^{15}$ One notable exception is Germany, where the total annual volume of congestion management actions has exceeded 15 terrawatthours (TWh) since 2015 (Bundesnetzagentur 2020). This volume corresponds to more than $2 \%$ of final German consumption. This outcome has occurred owing to increasing internal congestion between the north and south of the country. Most renewables are located in the north, and large load centers are in the south.

${ }^{16}$ After the February 2021 rolling blackouts in Texas, numerous calls were made to not require retail consumers to pay their extremely high electricity bills. These bills resulted from high wholesale electricity prices.

${ }^{17}$ Mann (2006) defines merit goods as goods "for which government interference with the aggregated willingness to pay increases utility." Kapstein and Busby $(2010,75)$ define them as "goods that are available to everyone regardless of income."

${ }^{18}$ Negative or zero prices are not a problem in and of themselves. However, their efficiency implications depend on their cause. If their cause is an out-of-market payment, such as a production tax credit, then they may introduce inefficiencies. If their cause is generation units offering negative prices to stay online, then they may be efficient owing to high shutdown or startup costs.

19 The marginal block of supply for some thermal power plants may be from a generation unit whose marginal cost exceeds its average cost for the last part of its operating range (Felder and Peterson 1997). In this case, the marginal generator's (or marginal block of generation's) supply curve intersects the demand curve. The resulting price is sufficient for the installed generation units to recover all their costs.

${ }^{20}$ This market can also be administered by U.S. states, as in the case of the Regional Greenhouse Gas Initiative.

${ }^{21}$ Renewable market standards may provide some resilience and adaptation capabilities, particularly when combined with other policies. For example, they may enable distributed solar facilities to operate without jeopardizing utility workers' safety when the remainder of the distribution system is without power.

22 Power systems have supervisory control and data acquisition systems to identify and isolate near instantaneous faults. They rely upon markets to ensure sufficient ancillary services to manage changes in real power. Changes in reactive power are addressed via non-market means, such as transmission planning and operations and generation interconnection requirements.

${ }^{23}$ If other generation resources, such as nuclear units in several U.S. states, receive out-of-market payments, then similar efficiency concerns arise. 


\section{References}

Abbott, Malcolm, and Bruce Cohen. 2019.

"Maintaining the Security of Supply in the Australian National Electricity Market with Higher Levels of Renewable Energy." The Electricity Journal 32(9):106645.

Ahmadyar, Ahmad Shabir, Shariq Riaz, Gregor Verbič, Archie Chapman, and David J. Hill. 2017. "A Framework for Assessing Renewable Integration Limits with Respect to Frequency Performance." IEEE Transactions on Power Systems 33(4):444453. DOI: 10.1109/tpwrs.2017.2773091

Anandarajah, Gabrial, Neil Strachan, Paul Ekins, Ramachandran Kannan, and Nick Hughes. 2009. Pathways to a Low Carbon Economy: Energy Systems Modelling. London: UK Energy Research Centre.

Arentsen, Maarten J., and Rolf W. Künneke. 1996. "Economic Organization and Liberalization of the Electricity Industry: In Search of Conceptualization." Energy Policy 24(6):541-52. DOI: 10.1016/0301-4215(96)00044-4

Barbose, Galen, Ryan Wiser, Jenny Heeter, Trieu Mai, Lori Bird, Mark Bolinger, Alberta Carpenter, Garvin Heath, David Keyser, Jordan Macknick, Andrew Mills, and Dev Millstein. 2016. "A

Retrospective Analysis of Benefits and Impacts of US Renewable Portfolio Standards." Energy Policy 96:645-60. DOI: 10.1016/j.enpol.2016.06.035

Billinton, Roy, and Ronald N. Allan. 1984.

"Power-system Reliability in Perspective." Electronics and Power 30(3):231-6.

- - - 2003. "Reliability of Electric Power Systems: An Overview." In Handbook of Reliability Engineering, edited by Hoang Pham, 511-28. London: Springer-Verlag.
Blazquez, Jorge, Rolando Fuentes-Bracamontes, Carlo Andrea Bollino, and Nora Nezamuddin. 2018. "The Renewable Energy Policy Paradox." Renewable and Sustainable Energy Reviews 82:15. DOI: 10.1016/j.rser.2017.09.002

Blazquez, Jorge, Rolando Fuentes, and Baltasar Manzano. 2020. "On Some Economic Principles of the Energy Transition." Energy Policy 147:111807. DOI: 10.1016/j.enpol.2020.111807

Boasson, Elin Lerum. 2020. "Europeanization of Renewables Support." In Comparative Renewables Policy, edited by Elin Lerum Boasson, Merethe Dotterud Leiren, and Jørgen Wettestad, 58-72. Abingdon: Routledge. DOI : 10.4324/9780429198144-5

Boiteux, Marcel. 1949. "La Tarification des Demandes en Pointe." Revue Generale de l'Electricite 58:157-79.

Boiteux, Marcel. 1960. "Peak-load Pricing." The Journal of Business 33(2):157-79. DOI: $10.1086 / 294331$

Bompard, Ettore, Audun Botterud, Stefano Corgnati, Tao Huang, Mehdi Jafari, Pierluigi Leone, Stefano Mauro, Giuseppe Montesano, Carlo Papa, and Francesco Profumo. 2020. "An Electricity Triangle for Energy Transition: Application to Italy." Applied Energy 277:115525. DOI: 10.1016/j. apenergy.2020.115525

Brohé, Arnaud, and Sylvain Burniaux. 2015. "The Impact of the EU ETS on Firms' Investment Decisions: Evidence from a Survey." Carbon Management 6(5-6):221-31. DOI: 10.1080/17583004.2015.1131384 
Brown, Tom W., Tobias Bischof-Niemz, Kornelis Blok, Christian Breyer, Henrik Lund, and Brian V. Mathiesen. 2018. "Response to 'Burden of Proof: A Comprehensive Review of the Feasibility of $100 \%$ Renewable-electricity Systems'." Renewable and Sustainable Energy Reviews 92:834-47. DOI: 10.1016/j.rser.2018.04.113

Brown, Tom, and Lina Reichenberg. 2020. Decreasing Market Value of Variable Renewables Is a Result of Policy, Not Variability. arXiv preprint arXiv:2002.05209.

Bundesnetzagentur, 2020. "Publications on Network and Security System from the Bundesnetzagentur." https://www.bundesnetzagentur.de/EN/ Areas/Energy/Companies/SecurityOfSupply/ NetworkSecurity/Network_security_node.html.

Chapman, Andrew J., and Kenshi Itaoka. 2018. "Energy Transition to a Future Low-carbon Energy Society in Japan's Liberalizing Electricity Market: Precedents, Policies and Factors of Successful Transition." Renewable and Sustainable Energy Reviews 81:2019-27. DOI: 10.1016/j.rser.2017.06.011

Cretì, Anna, and Fulvio Fontini. 2019. Economics of Electricity: Markets, Competition and Rules. Cambridge: Cambridge University Press.

Crew, Michael A., Chitru S. Fernando, and Paul R. Kleindorfer. 1995. "The Theory of Peak-load Pricing: A Survey." Journal of Regulatory Economics 8(3):215-48. DOI: 10.1007/bf01070807

De Nooij, Michiel, Rogier Lieshout, and Carl Koopmans. 2009. "Optimal Blackouts: Empirical Results on Reducing the Social Cost of Electricity Outages Through Efficient Regional Rationing." Energy Economics 31(3):342-7. DOI: 10.1016/j. eneco.2008.11.004
De Vries, Laurens James. 2005. "Securing the Public Interest in Electricity Generation Markets: The Myths of the Invisible Hand and the Copper Plate." Ph.D. Diss. Delft University of Technology.

Denholm, Paul, and Robert M. Margolis. 2007. "Evaluating the Limits of Solar Photovoltaics (PV) in Traditional Electric Power Systems." Energy Policy 35(5):2852-61. DOI: 10.1016/j.enpol.2006.10.014

Dilnot, Andrew, and Dieter Helm. 1987. "Energy Policy, Merit Goods and Social Security." Fiscal Studies 8(3):29-48.

Dworkin, Michael H., and Rachel Aslin Goldwasser. 2007. "Ensuring Consideration of the Public Interest in the Governance and Accountability of Regional Transmission Organizations." Energy LJ 28:543.

Eisenack, Klaus, and Mathias Mier. 2019. "Peak-load Pricing with Different Types of Dispatchability." Journal of Regulatory Economics 56(2):105-24. DOI: 10.1007/s11149-019-09394-9

Elshurafa, Amro M. 2020. "The Value of Storage in Electricity Generation: A Qualitative and Quantitative Review." Journal of Energy Storage 32:101872. DOI: 10.1016/j.est.2020.101872

European Commission. 2009. "Directive 2009/28/ EC of the European Parliament and of the Council of 23 April 2009 on the Promotion of the Use of Energy from Renewable Sources and Amending." https://eur-lex.europa.eu/legal-content/EN/ ALL/?uri=CELEX\%3A32009L0028.

European Commission. 2014. "Communication from the Commission - Guidelines on State Aid for Environmental Protection and Energy 20142020." https://eur-lex.europa.eu/legal-content/EN/ TXT/?uri=CELEX\%3A52014XC0628\%2801\%29. 
European Network of Transmission System Operators for Electricity (ENTSOE). 2018. CACM List of Information to ACER. Brussels: ENTSOE.

EU-SysFlex. 2018. "State-of-the-Art Literature Review of System Scarcities at High Levels of Renewable Generation. Deliverable D2.1 of the European EU-SysFlex project." http://eu-sysflex. com/wp-content/uploads/2018/12/D2.1_State-of-theArt_Literature_Review_of_System_Scarcities_at_ High_Levels_of_Renewable_Generation_V1.pdf.

Fabrizio, Kira R., Nancy L. Rose, and Catherine D. Wolfram. 2007. "Do Markets Reduce Costs? Assessing the Impact of Regulatory Restructuring on US Electric Generation Efficiency." American Economic Review 97(4):1250-77. DOI: 10.1257/ aer.97.4.1250

Felder, Frank A. 2001. "'An Island of Technicality in a Sea of Discretion': A Critique of Existing Electric Power Systems Reliability Analysis and Policy." The Electricity Journal 14(3):21-31. DOI: 10.1016/ s1040-6190(01)00183-x

- - - 2011. "Examining Electricity Price Suppression Due to Renewable Resources and Other Grid Investments." The Electricity Journal 24(4):34-46. DOI: 10.1016/j.tej.2011.04.001

- - - 2020. "Market Versus Planning Approaches to Transmission and Distribution Investment." In Transmission Network Investment in Liberalized Power Markets, edited by Mohammad Reza Hesamzadeh, Juan Rosellón, and Ingo Vogelsang, 257-74. Cham: Springer. DOI: 10.1007/978-3-030-47929-9_9

Felder, Frank A., and Steve R. Peterson. 1997. "Market Power Analysis in a Dynamic Electric
Power." The Electricity Journal 10(3):12-19. DOI: 10.1016/s1040-6190(97)80373-9

Goldthau, Andreas. 2014. "Rethinking the Governance of Energy Infrastructure: Scale, Decentralization and Polycentrism." Energy Research \& Social Science 1:134-140. DOI: 10.1016/j.erss.2014.02.009

Green, Richard. 2005. "Electricity and Markets." Oxford Review of Economic Policy 21(1):67-87. DOI: 10.1093/oxrep/gri004

Grubb, Michael, and David Newbery. 2007. "Pricing Carbon for Electricity Generation: National and International Dimensions." Cambridge Working Papers in Economics.

Hall, J. D., Robert J. Ringlee, and Allen J. Wood. 1968. "Frequency and Duration Methods for Power System Reliability Calculations: I-Generation System Model." IEEE Transactions on Power Apparatus and Systems 9:1787-96. DOI: 10.1109/tpas.1968.291986

Heard, Benjamin P., Barry W. Brook, Tom M.L. Wigley, and Corey J.A. Bradshaw. 2017. "Burden of Proof: A Comprehensive Review of the Feasibility of 100\% Renewable-electricity Systems." Renewable and Sustainable Energy Reviews 76:1122-33. DOI: 10.1016/j.rser.2017.03.114

Hines, Paul, Jay Apt, and Sarosh Talukdar. 2009. "Large Blackouts in North America: Historical Trends and Policy Implications." Energy Policy 37(12):524959. DOI: 10.1016/j.enpol.2009.07.049

Hogan, William W. 2014. "Electricity Market Design and Efficient Pricing: Applications for New England and Beyond." The Electricity Journal 27(7):23-49. DOI: 10.1016/j.tej.2014.07.009 
Jacobson, Mark Z., Mark A. Delucchi, Zack A.F. Bauer, Savannah C. Goodman, William E. Chapman, Mary A. Cameron, Cedric Bozonnat, Liat Chobadi, Hailey A. Clonts, Peter Enevoldsen, Jenny R. Erwin, Simone N. Fobi, Owen K. Goldstrom, Eleanor M. Hennessy, Jingyi Liu, Jonathan Lo, Clayton B. Meyer, Sean B. Morris, Kevin R. Moy, Patrick L. O'Neill, Ivalin Petkov, Stephanie Redfern, Robin Schucker, Michael A. Sontag, Jingfan Wang, Eric Weiner, and Alexander S. Yachanin. 2017. "100\% Clean and Renewable Wind, Water, and Sunlight All-sector Energy Roadmaps for 139 Countries of the World." Joule 1(1):108-21.

Jaffe, Adam B., and Frank A. Felder. 1996. "Should Electricity Markets Have a Capacity Requirement? If So, How Should It Be Priced?" The Electricity Journal 9(10):52-60. DOI: 10.1016/ s1040-6190(96)80157-6

Johnson, Samuel C., Joshua D. Rhodes, and Michael E. Webber. 2020. "Understanding the Impact of Non-Synchronous Wind and Solar Generation on Grid Stability and Identifying Mitigation Pathways." Applied Energy 262:114492. DOI: 10.1016/j.apenergy.2020.114492

Joskow, Paul L. 2006a. "Introduction to Electricity Sector Liberalization: Lessons Learned from Cross-Country Studies." Electricity Market Reform: An International Perspective 1:1-32. DOI: 10.1016/ b978-008045030-8/50002-3

- - . 2006b. "Markets for Power in the United States: An Interim Assessment." The Energy Journal 27(1):1-36. DOI: 10.5547/ issn0195-6574-ej-vol27-no1-2

- - - 2006c. "Competitive Electricity Markets and Investment in New Generating Capacity." AEIBrookings Joint Center Working Paper 06-14.
Kahnamouei, Ali Shakeri, Tohid Ghanizadeh Bolandi, and M-R. Haghifam. 2017. "The Conceptual Framework of Resilience and Its Measurement Approaches in Electrical Power Systems." IET International Conference on Resilience of Transmission and Distribution Networks (RTDN 2017), 1-11.

Kančev, Duško, and Marko Čepin. 2011. "Common Cause Failures: Explicit Modelling of Single Failure Event Within Different Common Cause Groups." Proceedings of NENE201, NSS.

Kapstein, Ethan B., and Joshua W. Busby. 2020. "Making Markets for Merit Goods: The Political Economy of Antiretrovirals." Global Policy 1(1):7590. DOI: 10.1111/j.1758-5899.2009.00012.x

Karbouj, Hazem, Zakir Hussain Rather, Damian Flynn, and Hassan W. Qazi. 2019. "Non-synchronous Fast Frequency Reserves in Renewable Energy Integrated Power Systems: A Critical Review." International Journal of Electrical Power \& Energy Systems 106:488-501. DOI: 10.1016/j. ijepes.2018.09.046

Koltsaklis, Nikolaos E., Athanasios S. Dagoumas, and Ioannis P. Panapakidis. 2017. "Impact of the Penetration of Renewables on Flexibility Needs." Energy Policy 109:360-9. DOI: 10.1016/j. enpol.2017.07.026

Kroposki, Benjamin. 2017. "Integrating High Levels of Variable Renewable Energy into Electric Power Systems." Journal of Modern Power Systems and Clean Energy 5(6):831-7. DOI: 10.1007/ s40565-017-0339-3

Léautier, Thomas-Olivier. 2019. Imperfect Markets and Imperfect Regulation: An Introduction to the Microeconomics and Political Economy of Power Markets. Cambridge, MA: MIT Press. 
Leslie, Gordon W., David I. Stern, Akshay Shanker, and Michael T. Hogan. 2020. "Designing Electricity Markets for High Penetrations of Zero or Low Marginal Cost Intermittent Energy Sources." The Electricity Journal 33(9):106847. DOI: https://doi. org/10.1016/j.tej.2020.106847

Löfgren, Åsa, Markus Wråke, Tomas Hagberg, and Susanna Roth. 2014. "Why the EU ETS Needs Reforming: An Empirical Analysis of the Impact on Company Investments." Climate Policy 14(5):53758. DOI: $10.1080 / 14693062.2014 .864800$

Lu, Yonglong, Nebojsa Nakicenovic, Martin Visbeck, and Anne-Sophie Stevance. 2015. "Policy: Five Priorities for the UN Sustainable Development Goals." Nature News 520(7548):432. DOI: doi. org/10.1038/520432a

Mann, Stefan. 2006. "Merit Goods in a Utilitarian Framework." Review of Political Economy 18(4):50920. DOI: 10.1080/09538250600915691

Matthewman, Steven, and Hugh Byrd. 2014.

"Blackouts: A Sociology of Electrical Power Failure." Lincoln Repository.

Mays, Jacob. 2021. "Missing Incentives for Flexibility in Wholesale Electricity Markets." Energy Policy 149:112010. DOI: 10.1016/j.enpol.2020.112010

Michaels, Robert J. 2008. "A National Renewable Portfolio Standard: Politically Correct, Economically Suspect." The Electricity Journal 21(3):9-28. DOI: 10.1016/j.tej.2008.03.003

Ovaere, Marten, Evelyn Heylen, Stef Proost, Geert Deconinck, and Dirk Van Hertem. 2019. "How Detailed Value of Lost Load Data Impact Power System Reliability Decisions." Energy Policy
132:1064-75. DOI: 10.1016/j.enpol.2019.06.058

Paiho, Satu, Heidi Saastamoinen, Elina Hakkarainen, Lassi Similä, Riku Pasonen, Jussi Ikäheimo, Miika Rämä, Markku Tuovinen, and Seppo Horsmanheimo. 2018. "Increasing Flexibility of Finnish Energy Systems-A Review of Potential Technologies and Means." Sustainable Cities and Society 43:509-23. DOI: 10.1016/j.scs.2018.09.015

Papaefthymiou, Georgios, and Ken Dragoon. 2016. "Towards 100\% Renewable Energy Systems: Uncapping Power System Flexibility." Energy Policy 92:69-82. DOI: 10.1016/j.enpol.2016.01.025

Petitet, Marie, Burcin Unel, Rolando Fuentes, and Frank A. Felder. 2021. "Climate and Power System Reliability in the Aftermath of the Texas Blackouts." IAEE Energy Forum. Third Quarter 2021, 12-16.

Phillips, Stephanie. 2019. "Federal Regulation for a Resilient Electricity Grid.” Ecology LQ 46:415.

Plotnek, Jordan J., and Jill Slay. 2021. "Power Systems Resilience: Definition and Taxonomy with a View Towards Metrics." International Journal of Critical Infrastructure Protection 33:100411. DOI: 10.1016/j.jijcip.2021.100411

Pollitt, Michael. 2009. "Evaluating the Evidence on Electricity Reform: Lessons for the South East Europe (SEE) Market." Utilities Policy 17(1):13-23. DOI: 10.1016/j.jup.2008.02.006

Pollitt, Michael G., and Karim L. Anaya. 2016. "Can Current Electricity Markets Cope with High Shares of Renewables? A Comparison of Approaches in Germany, the UK and the State of New York." The Energy Journal 37(S2):69-88. DOI: 10.5547/01956574.37.si2.mpol 
Schmidt, Tobias S., Nicolas Schmid, and Sebastian Sewerin. 2019. "Policy Goals, Partisanship and Paradigmatic Change in Energy Policy-Analyzing Parliamentary Discourse in Germany Over 30 Years." Climate Policy 19(6):771-86. DOI: 10.1080/14693062.2019.1594667

Sorrell, Steven. 2010. "Energy, Economic Growth and Environmental Sustainability: Five Propositions." Sustainability 2(6):1784-809. DOI: 10.3390/ su2061784

Spees, Kathleen, Travis Carless, Walter Graf, Sam Newell, Lily Mwalenga, Sean Chew, Frederick Corpuz, and Kathryn Peters. 2021. Alternative Resource Adequacy Structures for Maryland. Boston: The Brattle Group. Alternative Resource Adequacy Structures for Maryland Final Brattle Study March 2021.pdf

Tomain, Joseph P. 2015. "The Democratization of Energy." Vanderbilt Journal of Transnational Law 48:1125.

Tran, Thomas T.D., and Amanda D. Smith. 2017. "Evaluation of Renewable Energy Technologies and Their Potential for Technical Integration and Cost-effective Use Within the US Energy Sector." Renewable and Sustainable Energy Reviews 80:1372-88. DOI: 10.1016/j.rser.2017.05.228

United States Energy Information Administration (EIA). 2011. "Levelized Costs of New Generation Resources in the Annual Energy Outlook 2021." US Department of Energy, January.
Urpelainen, Johannes, and Joonseok Yang. 2019. "Global Patterns of Power Sector Reform, 19822013." Energy Strategy Reviews 23:152-62. DOI: 10.1016/j.esr.2018.12.001

Van den Bergh, Kenneth, and Erik Delarue. 2020. "Energy and Reserve Markets: Interdependency in Electricity Systems with a High Share of Renewables." Electric Power Systems Research 189:106537. DOI: 10.1016/j.epsr.2020.106537

Welton, Shelley. 2018. "Grasping for Energy Democracy." Michigan Law Review 116(4):581-644.

Welton, Shelley. 2021. "Rethinking Grid Governance for the Climate Change Era." California Law Review 109:209.

Zappa, William, Martin Junginger, and Machteld van den Broek. 2019. "Is a 100\% Renewable European Power System Feasible by 2050?" Applied Energy 233:1027-50. DOI: 10.1016/j.apenergy.2018.08.109

Zheng, Tongxin, and Eugene Litvinov. 2010. "On Ex Post Pricing in the Real-time Electricity Market." IEEE Transactions on Power Systems 26(1):153-64. DOI: 10.1109/tpwrs.2010.2050707 


\section{Notes}

(1) 


\section{About the Authors}

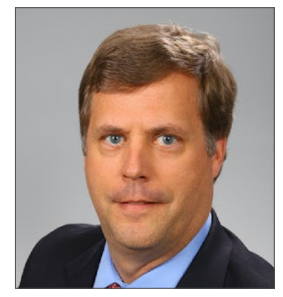

\section{Frank A. Felder}

Frank is an engineer, energy policy analyst, and program director for Energy Transitions and Electric Power. Prior to joining KAPSARC, Frank was a research professor at the School of Planning and Public Policy at Rutgers University, the Director of the Rutgers Energy Institute, and the Director of the Center for Energy, Economics and Environmental Policy. In those roles, he conducted original and applied research in the areas of electric power system modeling, clean energy policies, and climate change for academic foundations, government agencies, and energy utilities. He has also worked as an economic consultant and nuclear engineer.

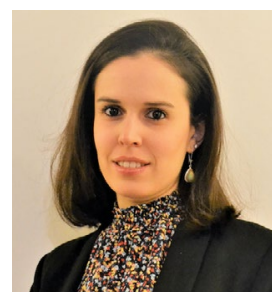

\section{Marie Petitet}

Marie is a senior research associate in the Energy Transitions and Electric Power program at KAPSARC. Her current research focuses include power system modeling and market designs for energy transitions. Prior to joining KAPSARC, Marie worked as a research engineer within the Research and Development (R\&D) unit of the utility group EDF in Paris, France. During her EDF journey, she worked on long-term and short-term electricity market design, European scale transmission grids, and smart-charging opportunities for electric vehicles.

Marie holds a Ph.D. in economics from Dauphine University, PSL (France), an M.Sc. in environmental and energy economics from École des Ponts ParisTech (France), and an M.Sc. in engineering from the ENSTA Institut Polytechnique de Paris (France).

\section{About the Project}

This paper is part of the project "Innovations in electricity markets, network regulations, low-carbon investments and technologies" under KAPSARC's Energy Transitions and Electric Power program. This project aims to provide insights on the transformation of the Saudi electricity sector. This transformation is characterized by a willingness to increase the share of renewables and replace liquid fuels with natural gas. It must also ensure fiscal balance, expand electricity exports, produce green hydrogen and diversify the Saudi economy through localization. This project provides insights into this transition by discussing and learning from electricity markets worldwide. 
INAPSARC

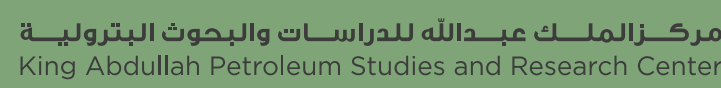

www.kapsarc.org 